\title{
CONSCIÊNCIA E FENÔMENOS MENTAIS INCONSCIENTES: AS VISÕES DE DAVID ARMSTRONG E JOHN SEARLE ${ }^{1}$
}

Tárik de Athayde Prata (UFPE) $)^{2}$

tarik.de_athayde_prata@alumni.uni-heidelberg.de

Resumo: o artigo examina as concepções de consciência, bem como as concepções de fenômenos mentais inconscientes, de David Armstrong e John Searle. Enquanto Armstrong entende a consciência como decorrente de uma percepção de segunda ordem, de modo que um fenômeno inconsciente é apenas um fenômeno mental que não é percebido, Searle entende a consciência como um estado global, o que torna sua visão do inconsciente mais complicada. Estados mentais inconscientes não passam de padrões de atividade neuronal, padrões que são capazes de causar estados mentais conscientes nas circunstâncias adequadas. Porém, enquanto a teoria de Armstrong é perfeitamente coerente, a visão de Searle se mostra inconsistente, pois a eficácia causal que ele atribui aos fenômenos inconscientes é incompatível com o papel fundamental que ele atribui à consciência no domínio dos fenômenos mentais.

Palavras-chave: consciência, percepção, inconsciente, eficácia causal.

\section{INTRODUÇÃO}

É amplamente difundido no debate filosófico o entendimento de que a palavra "consciência" pode ser usada para expressar diferentes conceitos (cf. Brentano, 1924, p. 141

\footnotetext{
${ }^{1}$ Recebido: 08-10-2017/ Aceito: 28-07-2020/ Publicado on-line: 05-10-2020.

${ }^{2}$ Professor Adjunto do Departamento de Filosofia da Universidade Federal de Pernambuco (UFPE), Recife, PE, Brasil.
} 
[101] ; Chalmers, 1995, p. 200; Block, 1997, p. 375). Em um sentido estritamente psicológico ${ }^{4}$, essa palavra pode ser empregada para designar (entre outras coisas) uma entidade (cf. Husserl, 1984, p. 356 [295]'; Sartre, 1966, p. 15 [184]), ou uma característica exemplificável por diversas entidades (cf. Gennaro, 1996, p. 4; Rosenthal, 1997, p. 729; Kriegel, 2004, p. 183). No primeiro caso, a entidade em questão pode ser algo mais amplo e complexo, por um lado, ou algo mais simples e delimitado, por outro lado. Se usamos "consciência" para designar uma entidade, esta poderia ser o psiquismo de um sujeito psicológico, por exemplo, ou um fenômenos psíquico que existe nesse sujeito, como uma crença, um desejo ou um sentimento. ${ }^{6}$ Já se usamos esse termo para designar algum tipo de característica (ou propriedade), podemos discernir o caso de uma propriedade intrínseca de seu portador do caso de uma propriedade extrínseca, quando o portador exemplifica a propriedade em virtude de suas relações com outras entidades, de modo que ele pode existir mesmo quando não exemplifica essa propriedade relacional.

O fato é que se usamos a palavra "consciência" para

\footnotetext{
${ }^{3} \mathrm{O}$ primeiro número de página é da edição na língua original, enquanto o número entre colchetes é o da tradução em língua inglesa.

${ }^{4}$ De acordo com Güven Güzeldere, a expressão "consciência” pode ter, além de uma sentido psicológico (cf. Güzeldere, 1997, p. 9), um sentido moral (cf. Güzeldere, 1997, p. 49, nota de rodapé $\mathrm{n}^{\circ}$ 12) ou um sentido social (cf. Güzeldere, 1997, p. 9).

${ }^{5} \mathrm{O}$ primeiro número de página é da edição na língua original, enquanto o número entre colchetes é o da tradução em português.

${ }^{6}$ Essa distinção aparece na seguinte passagem do livro O imaginário, de Sartre: "Usaremos o termo 'consciência' não para designar a mônada e o conjunto de suas estruturas psíquicas, mas para nomear cada uma dessas estruturas em sua particularidade concreta. Falaremos, portanto, de consciência da imagem, consciência perceptiva, etc., inspirando-nos num dos sentidos alemães da palavra Bewusstsein.” (Sartre, 1996, p. 13).
} 
nos referir a um fenômeno psíquico (como uma imagem mental, uma percepção ou uma crença) esse uso pode ser interpretado de modo que o fenômeno psíquico em questão é necessariamente consciente ou, em outros termos, possui intrinsecamente a propriedade da consciência. Isto é, ao designar uma crença, ou uma percepção, como uma "consciência" (como faz, por exemplo, Sartre), isso pode ser entendido de modo que tal fenômeno, para existir, tem que ser consciente. Mas a tese de que a consciência é uma propriedade intrínseca dos fenômenos mentais, associada tradicionalmente ao pensamento de Descartes (cf. Rosenthal, 1986, p. 331; Armstrong, 1997, p. 721; Armstrong, 1999, pp. 14-16; Searle, 2004, p. 13), levanta importantes problemas, que precisam ser enfrentados por aqueles que pretendem defende-la. De fato, o autor do Discurso defendeu explicitamente que o pensamento - concebido por ele como a essência da alma - é algo de que sempre temos consciência (cf. Descartes, 1979, p. 169 [AT, VII, p. 160; AT, IX, p. 124$]^{7}$ ), um ponto de vista que o leva a rejeitar a ideia de fenômenos mentais inconscientes pois, para Descartes: "nenhum pensamento pode existir em nós do qual nos não estejamos conscientes no exato momento em que ele existe em nós" (AT, VII, p. 246; AT, IX, p. 190). ${ }^{8}$ Entretanto, no pensamento contemporâneo, surgiram questionamentos sobre se esta é uma visão sustentável. David Rosenthal afirma que essa concepção cartesiana da consciência, no que define todo fenômeno mental em termos de consciência,

\footnotetext{
${ }^{7}$ Entre colchetes estão indicadas as referências ao volume VII (latim) e ao volume IX (francês) da edição das obras de Descartes organizada por Charles Adam e Paul Tannery.

${ }^{8}$ Essa citação não está disponível na edição brasileira consultada para a redação do presente trabalho.
} 
inviabiliza qualquer explanação informativa sobre o que torna um estado mental um estado consciente, pois toda tentativa de explicação, formulada em termos psicológicos, já pressuporia aquilo que ela pretende explicar (cf. Rosenthal, 1986, p. 330), e a impossibilidade de uma explanação informativa, inclusive, reforçaria a sensação de um abismo entre o mental e o físico, já que no domínio físico não encontramos esse tipo de opacidade à explanação (cf. Ibid., p. 335).

Rosenthal, ele mesmo, propõe uma teoria para explicar a consciência (enquanto uma propriedade de estados mentais), que ele chama de teoria dos "pensamentos de ordem superior" (Higher-Order Thoughts). Mas, na verdade, essa teoria se insere em uma tradição que é bem mais antiga, remontando a importantes filósofos do passado, como John Locke (cf. Gennaro, 2004, p. 1) ou Immanuel Kant (cf. Armstrong, 1968, p. 95; Armstrong, 1997, p. 724). Trata-se das chamadas "Teorias de ordem superior" (cf. Van Gulick, 2012, p. 47), que são especialmente relevantes para pensar um aspecto da mente que, desde os trabalhos de Sigmund Freud (cf. Searle, 1992, p. 151 [218]; Gennaro, 1996, p. 6), assumiu imensa importância na pesquisa a respeito dos fenômenos mentais: o inconsciente. Uma série de conhecimentos desenvolvidos ao longo dos últimos cento e vinte anos indica que fenômenos mentais inconscientes desempenham um papel decisivo em nossa vida psicológica, de maneira que tais fenômenos não devem ser ignorados em nossas reflexões sobre o psiquismo.

E, uma vez que, de acordo com as teorias de ordem superior, a consciência de um estado mental é concebida como uma propriedade relacional, isto é, uma propriedade 
dependente da relação daquele estado mental com um outro estado mental, a ideia de fenômenos mentais inconscientes encontra lugar de modo mais fácil, pois o fenômeno inconsciente é apenas aquele que em um dado momento não se encontra nesse tipo de relação (com um outro estado mental), de modo que a propriedade de ser consciente não é essencial para a sua existência. Este foi o tipo de perspectiva defendida pelo filósofo australiano David Armstrong (1926-2014), que considerava a consciência apenas como um desenvolvimento sofisticado da mente, e não como o seu fundamento, ideia que o comprometia com a aceitação da existência de fenômenos mentais inconscientes (cf. Armstrong, 1968, p. 114; Armstrong, 1997, p. 724).

Armstrong assume, declaradamente, uma postura anticartesiana (cf. Armstrong, 1997, p. 721), porém, no cenário atual, ainda existem autores que defendem a velha visão da consciência como o fundamento da mente, como a essência dos fenômenos mentais, que é um tipo de perspectiva no qual a ideia de fenômenos mentais inconscientes não se integra de modo tão simples. O filósofo norte americano John R. Searle (1932- ) defende esse tipo de concepção. Para ele, qualquer fenômeno psíquico só pode ser concebido como, propriamente, mental por meio de suas relações com a consciência (cf. Searle, 1992, p. 18 [31]; Searle, 1992, p. 84 [125-26]). Searle entende a consciência como um estado global, uma unidade subjacente, da qual os diversos estados mentais particulares são simples modos (ou seja, modificações). Em consonância com essa visão da consciência, ele defende uma concepção disposicional dos fenômenos inconscientes: eles não seriam fenômenos mentais efetiva- 
mente existentes, mas sim disposições, fundadas em processos cerebrais (não conscientes e não mentais) que teriam a capacidade de causar fenômenos mentais conscientes nas circunstâncias adequadas. ${ }^{9}$ Sendo assim, Searle aceita a existência de fenômenos inconscientes, mas afirma que eles não existem de maneira realmente mental, pois, enquanto eles são inconscientes, eles existem como simples processos no cérebro, capazes de causar genuínos fenômenos mentais (pelo menos em princípio). ${ }^{10}$

Isso parece significar que as concepções dos dois filósofos contemporâneos são profundamente distintas. Enquanto na visão de Armstrong um fenômeno mental inconsciente é apenas um fenômeno que não percebemos, mas que existe da mesma forma que um fenômeno consci-

\footnotetext{
9 "A grande variedade de tipos de propriedades que são compreendidos por termos tais como 'disposição', 'poder', 'potencial', 'tendência', 'capacidade' e 'propensão', compartilham uma estrutura genérica comum. Eles são atribuídos a coisas e substâncias. Entretanto, em todos os casos a estrutura básica dessa atribuição é de forma condicional. Atribuir uma disposição a uma coisa ou substância é dizer que se certas condições são alcançadas, então a coisa ou substância vai se comportar de um certo modo, ou provocar um certo efeito - isto é, um certo resultado vai ocorrer. Um solo fértil é aquele do qual é verdadeiro dizer que se sementes são plantadas e cuidadas adequadamente, elas vão crescer e se tornar plantas crescidas. Uma partícula com carga negativa é aquela da qual é verdadeiro dizer que, se for trazida para as proximidades de uma outra partícula negativamente carregada, ela sofrerá uma força de repulsão." (Harré, 2001, p. 97). O autor, claramente, tem em vista disposições de objetos físicos, mas não é difícil transpor a noção de propriedade disposicional para o caso dos fenômenos mentais inconscientes.

${ }^{10}$ É interessante notar que a visão disposicional do inconsciente, que entende fenômenos inconscientes como não mentais, mas sim como simples disposições codificadas na estrutura física do cérebro, foi conhecida, mas prontamente recusada por Freud. Nas palavras do fundador da psicanálise: "Neste ponto temos que estar preparados para ser confrontados com a objeção filosófica de que a representação latente não estaria disponível como objeto da psicologia, mas apenas como disposição física [physische Disposition] para a recriação do mesmo fenômeno psíquico, a saber, a mesmíssima representação. Mas poderíamos retrucar a isso que uma tal teoria ultrapassa muito o domínio da psicologia propriamente dita, que ela simplesmente contorna o problema, ao insistir que 'consciente' e 'psíquico' são conceitos idênticos, e que essa teoria está claramente errada ao questionar o direito da psicologia de elucidar através de seus próprios meios um de seus fatos mais típicos, como a memória." (Freud, 1982, p. 29). A tradução das citações em língua estrangeira foi feita pelo autor do presente artigo.
} 
ente; na visão de Searle, um fenômeno inconsciente é essencialmente distinto de um fenômeno consciente, sendo o vínculo entre eles a capacidade dos processos neuronais (objetivos) de causarem o fenômeno consciente (subjetivo), nas devidas circunstâncias.

Porém, em sua teoria dos fenômenos mentais inconscientes, Searle faz uma afirmação que me parece incompatível com sua própria perspectiva sobre o inconsciente: ele afirma que fenômenos inconscientes, enquanto tais, possuem eficácia causal, o que, no meu modo de entender, o compromete com a tese de que os fenômenos mentais tem que possuir características mentais independentemente da consciência (exatamente como pensa Armstrong). A tese do presente trabalho é que, apesar de suas grandes diferenças (sendo a principal a diferença do papel da consciência no domínio psíquico), as teorias de Searle e de Armstrong não são completamente distintas, e isso mostra uma incoerência na teoria de Searle, pois não deveria haver espaço, nessa teoria, para uma existência mental independente da consciência. Após um exame da visão de Armstrong (seção 2) e da visão de Searle (seção 3), será discutida a maneira como a atribuição de eficácia causal aos fenômenos inconscientes compromete Searle com a existência de características mentais independentes da consciência (seção 4), de maneira que a perspectiva de uma existência fundamentalmente inconsciente dos fenômenos mentais se mostra mais adequada (seção 5). Em outras palavras, a visão cartesiana, ainda hoje defendida por Searle, não se sustenta, de modo que ela deve ser substituída por uma visão mais contemporânea, segundo a qual a consciência não é a essência da mente. 


\section{A CONCEPÇÃO DE CONSCIÊNCIA DE ARMSTRONG}

David Armstrong foi um dos grandes expoentes da filosofia da mente ao longo do século XX - e início do século XXI - tendo empreendido importantes reflexões a respeito da consciência. No texto "What is Consciousness?" (publicado originalmente em 1981), Armstrong traça algumas distinções conceituais bastante fecundas para a nossa compreensão da consciência e expõe as linhas básicas de sua concepção acerca dela. Ele propôs a distinção entre consciência mínima (minimal consciousness), consciência perceptiva (perceptual consciousness) e aquilo que seria o aspecto mais sofisticado e interessante da consciência, aspecto que ele chama de consciência introspectiva (introspective consciousness).

É importante ter clareza, logo de início, que um dos principais objetivos de Armstrong com sua teoria é o de refutar a visão de que a consciência é o aspecto mais importante da mente, o que o coloca em total oposição a Searle. O filósofo australiano defende uma perspectiva na qual a consciência, na qualidade de um fenômeno evolucionariamente tardio, desempenha um importante papel em nossas interações com o meio, na medida em que ela possibilita uma integração dos fenômenos psíquicos, que nos permite realizar ações extremamente sofisticadas (cf. Armstrong, 1997, p. 726). Porém, a consciência seria uma capacidade refinada que se aplica a processos psicológicos que existem independentemente dela, de modo que ela não seria o fundamento dos fenômenos mentais. Armstrong formula essa 
sua visão como uma rejeição à concepção cartesiana da mente:

Existe, porém, uma tese sobre a consciência que eu creio poder ser rejeitada com confiança: a doutrina de Descartes de que a consciência é a essência da mentalidade. Esse ponto de vista assume que podemos explicar a mentalidade em termos de consciência. Eu penso que a verdade vai na direção contrária. Na verdade, no sentido mais interessante da palavra 'consciência', a consciência é o creme sobre o bolo da mentalidade, um desenvolvimento especial e sofisticado da mentalidade. Ela não é o bolo em si. (Armstrong, 1997, p. 721).

Examinemos, portanto, as três noções de consciência distinguidas por Armstrong. Consciência mínima, de acordo com ele, tem lugar quando há qualquer tipo de atividade mental, mesmo em circunstâncias nas quais o sujeito seria descrito por terceiros como estando inconsciente. Ele dá o exemplo de matemáticos que adormecem pensando sobre um problema de cálculo e que encontram a solução, num lampejo, após o despertar. Em tais situações, é inevitável supor que houve algum tipo de processo mental, uma ponderação acerca do problema, mesmo que o indivíduo estivesse desacordado (cf. Armstrong, 1997, p. 722). Já a consciência perceptiva ocorre quando há a percepção de objetos e estados de coisas no mundo circundante, e não uma experiência pseudo perceptiva, como uma alucinação ou um sonho (cf. Armstrong, 1997, p. 723), o que nos torna capazes de interagir de modo inteligente com o meio.

Entretanto, esses dois conceitos, consciência mínima e consciência perceptiva, são incapazes de dar conta plenamente do fenômeno da consciência, pois, na visão de Armstrong, é possível que um sujeito desempenhe atividade 
mental e possua consciência perceptiva de algo, e mesmo assim falte a ele algo fundamental para aquilo que chamaríamos de consciência em seu sentido pleno. Para elucidar isso, ele escolhe um exemplo tomado de situações em que pessoas precisam dirigir veículos por longas distâncias durante a noite. Segundo ele, existem situações nas quais motoristas de caminhão, repentinamente, se apercebem que se deslocaram por uma distância significativa, sem que eles tenham ideia de como chegaram ali (cf. Armstrong, 1968, p. 93; Armstrong, 1997, p. 723). ${ }^{11}$ Podemos imaginar uma circunstância na qual um motorista, trafegando por uma região com a qual está familiarizado, atravessa a saída de um determinado município e repentinamente, observando a quilometragem da rodovia, se apercebe de ter percorrido uma certa distância sem ter lembrança de nada do que fez para se deslocar até aquele local. ${ }^{12}$ Em uma tal situação, existe tanto atividade mental (já que o sujeito efetivou uma série complexa de movimentos corporais, para poder dirigir) quanto consciência perceptiva (já que o sujeito tem que ter percebido a estrada, suas curvas, seus eventuais obstáculos, para conseguir percorrer aquela distância). Mesmo assim, parece faltar algo para podermos considerar que o motorista (ou seus estados mentais) estivesse plenamente consciente, e Armstrong chama isso de consciência introspectiva (introspective consciousness), algo que ele entende segundo o modelo da consciência perceptiva. De acordo com

\footnotetext{
${ }^{11}$ Em meu trabalho como professor conheci pessoas que relataram ter vivenciado esse tipo de situação mencionada por Armstrong.

${ }^{12}$ Podemos imaginar também, uma situação na qual uma pessoa, sob o efeito de medicação, realiza uma série de ações, das quais posteriormente não guarda a menor lembrança.
} 
ele "consciência não é mais do que a ciência [awareness] (percepção) dos estados mentais internos pela pessoa que possui esses estados mentais. Se é assim, então a consciência é simplesmente um outro estado mental, dirigido aos estados internos originais" (Armstrong, 1968, p. 94, grifo meu). A concepção da consciência como uma percepção dos fenômenos mentais é bastante antiga, e Armstrong afirma estar, simplesmente, defendendo a posição de Kant (cf. Armstrong, 1968, p. 95; Armstrong, 1997, p. 724). De acordo com a visão articulada por Armstrong "pela percepção sensorial nos tornamos cientes das ocorrências físicas que estão tendo lugar em nosso ambiente e em nosso corpo. Pelo sentido interno nos tornamos cientes das ocorrências que estão tendo lugar em nossa própria mente." (Armstrong, 1968, p. 95).

É importante perceber que ele emprega o termo "introspecção" para se referir não apenas ao exame atento e deliberado dos próprios estados mentais, que é o uso mais comum do termo, mas também para se referir à simples apreensão (supostamente) perceptiva de um estado mental, que torna esse estado consciente. Em outras palavras, Armstrong usa a expressão "consciência introspectiva" para se referir tanto ao que David Rosenthal designa como consciência introspectiva quanto ao que ele designa como consciência não introspectiva ${ }^{13}$ - o que não posso deixar de

\footnotetext{
13 "Será útil traçar uma segunda distinção preliminar. Quando prestamos atenção deliberadamente ao estado mental no qual nos encontramos, estamos introspectivamente conscientes desse estado. Isso é diferente do modo como estados mentais são conscientes quando não estamos deliberadamente focando nossa atenção sobre eles. Introspecção é consciência atenta e deliberada de nossos estados mentais. É algo relativamente raro, e é algo mais elaborado do que a maneira na qual estados mentais são ordinariamente conscientes. Quando realizamos introspecção, não estamos apenas cientes [aware] do estado mental em que estamos, nós estamos cientes de estarmos ciCont.
} 
perceber como uma imperfeição da terminologia de Armstrong. Ele chama o exame deliberado dos próprios estados mentais de introspecção propriamente dita (introspection proper) e chama a simples apreensão perceptiva de um estado mental de introspecção por reflexo (reflex introspection), o que, no meu modo de entender, deixa a diferença entre esses dois tipos de apreensão um pouco obscura ${ }^{14}$.

Voltando à noção de consciência introspectiva de Armstrong, é importante notar que, no caso do motorista de caminhão, apesar de haver efetivamente consciência, no sentido de haver atividade mental (consciência mínima) e percepção (consciência perceptiva) - cf. Armstrong, 1997, p. 723 - mesmo assim faltava uma atividade mais refinada, que é a atividade de perceber pelo menos alguns elementos da atividade mental que ocorria no indivíduo (fosse a percepção externa, fossem outras atividades mentais). Para enfatizar sua crença de que havia uma forma de consciência naquela situação peculiar, Armstrong nos lembra que:

Um propósito foi alcançado com sucesso naquele período: o de dirigir um veículo através da estrada. Esse propósito demandou que várias sub-rotinas complexas fossem efetuadas, e efetuadas em pontos apropriados (por exemplo, talvez o breque ou a embreagem tenham sido usados). Esses atos não foram deliberados? [purposeful] Acima de tudo, como é possível dirigir um veículo por quilômetros ao longo de uma estrada se não se está percebendo essa estrada? O motorista tem que ser capaz de ver para onde está indo, de modo a poder ajus-

\footnotetext{
entes dele. A diferença entre consciência introspectiva e não introspectiva emerge vividamente se notarmos que, quando um estado é consciente de modo não introspectivo, ele normalmente tem o potencial de ser um objeto de introspecção" (Rosenthal, 1997, p. 730).

${ }^{14}$ Sobre o argumento de Armstrong a favor do seu uso peculiar do termo "introspecção" cf. Armstrong, 1968, p. 95.
} 
tar a rota apropriadamente. Teria de ser admitido, ao menos, que em tal caso, os olhos e o cérebro tem de ter sido estimulados exatamente do mesmo modo que são estimulados em casos comuns de percepção. Por que então negar que ocorreu percepção? Assim, parece que consciência mínima e consciência perceptiva estão presentes. Mas alguma outra coisa está faltando: consciência no sentido mais interessante da palavra. (Armstrong, 1997, p. 723; cf. Armstrong, 1968, p. 93-94).

Nessa passagem, ele afirma claramente que o motorista dispõe de consciência, em algum sentido desse termo, embora careça de consciência em sua forma mais importante, o que pode sugerir que o motorista se encontra em um estado alterado de consciência, alterado pela sua condição de sonolência (assim como poderia ser alterado pela ação de alguma droga ou por causa de algum trauma - cf. a seguir a situação de um acidente narrada por Searle). Mas ao mesmo tempo em que há consciência (atividade mental e percepção) falta ao motorista "algo que se assemelha à percepção” (Armstrong, 1997, p. 724), que não está dirigido nem ao ambiente externo nem à condição do próprio corpo, e sim dirigido à própria atividade mental do indivíduo (incluindo a percepção externa).

Para Armstrong, a função biológica dessa percepção interna (percepção da própria atividade mental) é "sofisticar nosso processo mental no interesse de uma ação mais sofisticada” (Armstrong, 1997, p. 726), pois quando temos algum grau de ciência [awareness] de nossos próprios estados e atividades mentais é mais simples integrá-los para fazer com que trabalhem juntos da maneira complexa e sofisticada que é necessária para fins complexos e sofisticados. Discorrendo sobre a função biológica da mente, ele afirma: 
Processos mentais, biologicamente falando, são aqueles que caem entre o estímulo e a resposta. Sua função biológica é tornar a resposta mais sofisticada e mais eficiente. (...) Mas se uma [dada] sequência teleológica (...) é uma sequência de eventos na mente, isso significa que o agente tem que ser informado do que está, a cada momento, ocorrendo em sua mente. Assim, se nossa mente deve trabalhar entre o estímulo e a resposta, dirigida a um propósito, temos de ter ciência [awareness] de nossas mentes, isto é, tem que haver introspecção. (Armstrong, 1968, p. 163).

A introspecção fornece informações que possibilitam que processos paralelos na mente sejam integrados, de modo que problemas complexos possam ser solucionados. Nesse sentido, de acordo com Armstrong, "não é acidente que a consciência introspectiva completamente alerta surja tipicamente em situações problemáticas, situações em que rotinas padrão não nos levam adiante." (Armstrong, 1997, p. 727).

Esta última passagem citada alude à função da consciência de focar nossa atenção e, assim, direcionar nossos esforços para ações que se tornam necessárias, diante de um contexto problemático. Não posso deixar de mencionar que, muitas vezes, nos damos conta de que realizamos uma ação simples de modo totalmente inadvertido, mesmo que estivéssemos despertos e atentos a algo no ambiente ao redor, indicando que a consciência não foi necessária para a realização daquela ação simples. ${ }^{15}$

\footnotetext{
${ }^{15}$ Muitas vezes, em situações nas quais estamos plenamente despertos, dispondo de consciência perceptiva e também de consciência introspectiva nos termos de Armstrong, nos damos conta de que realizamos uma ação bastante simples sem que tivéssemos consciência dela. Uma pessoa que estivesse preparando um almoço, por exemplo, pode se lembrar de pegar um certo ingrediente na geladeira, e então se dar conta de que ele já está sobre a mesa, o que significa (na ausência de terceiros) que a própria pessoa já o havia pego em outro momento, mesmo sem ter se dado conta de que o havia pego.
} 
Essa função integradora da consciência introspectiva explica, de acordo com Armstrong, porque a introspecção leva naturalmente à ideia de um eu: se a introspecção é o meio de integração das diversas atividades mentais, é natural que essas atividades sejam vistas pelo próprio sujeito como algo unitário, isto é, sejam vistas como atividade de uma entidade contínua através do tempo. Essa conexão com a ideia de eu elucida parte do grande poder explicativo que Armstrong atribui ao conceito de consciência introspectiva, ou seja, a grande contribuição desse conceito para a compreensão de nossa própria existência psicológica.

Um outro aspecto desse poder explicativo está ligado, de acordo com ele, à conexão do conceito de introspecção com a memória de eventos particulares. Parte do estranhamento que a situação do motorista de caminhão nos provoca tem a ver, justamente, com o fato de uma sequência complexa de ações orientadas a um fim ter sido realizada sem que se tenha dela a menor lembrança. Ainda assim, em certo sentido, um processamento de memória tem de ter ocorrido:

Quando o motorista de caminhão de longa distância recobra a consciência introspectiva, ele não tem memória do que ocorreu enquanto ela estava ausente. Um tipo de processamento de memória não pode ter faltado a ele. Sua direção bem sucedida do veículo dependeu de ele ter sido capaz de reconhecer várias coisas pelo que elas são e trata-las de acordo com isso. Ele tem que ter sido capaz de reconhecer um certo grau de curva na estrada, um certo grau de pressão no acelerador, pelo que eles eram. Mas as coisas que aconteceram a ele durante o período de inconsciência introspectiva não foram registradas na sua memória de eventos. Ele vivia apenas no presente. (Armstrong, 1997, p. 727). 
Mas mesmo que algum tipo de memória tenha atuado no reconhecimento de certos aspectos do ambiente, a memória dos eventos que ocorreram na ausência da consciência introspectiva não foi fixada, o que leva Armstrong a supor que a consciência introspectiva desempenha algum papel importante nessa memória de eventos. Se isso for verdade, isso significa que a consciência introspectiva tem um papel decisivo na memória do eu, o que completa o quadro do poder explicativo que essa forma de consciência parece possuir no tocante à nossa vida mental. Veremos a seguir que a questão da memória do eu também tem um lugar de destaque nas análises de Searle a respeito da consciência (cf. Searle, 2004, p. 156).

A partir das premissas da teoria de Armstrong, nos vemos em um cenário onde a tese de que existem fenômenos mentais inconscientes encontra lugar com naturalidade. $\mathrm{Pa}$ ra ele, somos "forçados a admitir a possibilidade lógica de nos encontrarmos em um estado mental, mas não estarmos cientes de que nos encontramos nesse estado. Isso quer dizer, temos de admitir a possibilidade lógica de estados inconscientes.” (Armstrong, 1968, p. 113). Mas o fato é que uma teoria como a de Armstrong não é apenas logicamente compatível com a ideia de fenômenos mentais inconscientes. Muito mais do que isso, tal teoria está claramente comprometida com a existência de tais fenômenos, na medida em que a consciência de um estado mental é concebida por ele como decorrente do monitoramento desse estado mental por uma percepção, que é um estado mental distinto do primeiro. Isso significa que a consciência de um estado mental depende, segundo essa teoria, da relação desse esta- 
do com um outro estado mental (uma percepção), de modo que a consciência daquele estado se mostra como uma propriedade relacional, portanto extrínseca, sem a qual o estado mental pode continuar a existir. Nas palavras de Armstrong: "se a ciência introspectiva [introspective awareness] e seus objetos são 'existências distintas', como argumentamos, então tem que ser possível para os objetos que eles existam quando a ciência [awareness] não existe." (Armstrong, 1968, p. 114). Para ele, não precisamos nos restringir à possibilidade lógica do inconsciente, "pois existem suficientes casos empíricos que podem ser interpretados naturalmente como implicando a existência atual de estados mentais dos quais não estamos cientes" (Ibid., p. 114), como é o caso do próprio exemplo do motorista de caminhão discutido acima. Essa visão de que estados inconscientes possuem um enorme papel em nossa vida psíquica corresponde ao propósito dele de mostrar que a consciência não é a essência da mente. Ciente disso, ele chega a afirmar que sua teoria se assemelha à visão de Freud, diferindo dela apenas no aspecto de que a teoria de Armstrong não envolve a ideia de repressão (repression) dos fenômenos mentais intoleráveis por uma censura intrapsíquica. ${ }^{16}$ Para ilustrar a teoria de Armstrong, proponho o seguinte esquema:

\footnotetext{
16 "Em todos os momentos haverão estados e atividades de nossa mente dos quais nós não estamos introspectivamente cientes [aware]. Esses estados e atividades podem ser ditos estados e atividades mentais inconscientes em um bom sentido da palavra 'inconsciente' (ele é próximo do sentido freudiano, mas não há necessidade de sustentar que ele sempre envolve o mecanismo de repressão [repression]). Tais estados e atividades mentais inconscientes podem naturalmente envolver consciência mínima e/ou consciência perceptiva, na verdade as atividades envolvem consciência mínima por definição." (Armstrong, 1997, p. 724).
} 
Segunda ordem:

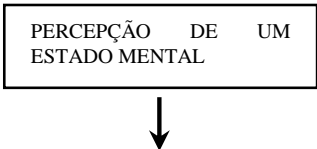

Primeira ordem:

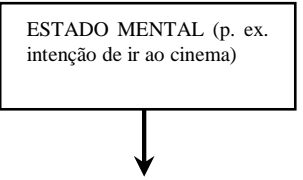

ESTADO MENTAL (p. ex. intenção de ir ao cinema)

Mundo

Extra-mental:

Em uma teoria como essa, a noção de fenômenos mentais inconscientes encontra lugar de maneira bastante simples. A situação se torna muito mais complicada quando passamos para a teoria de Searle, pois ele concebe a consciência de um modo, em certo sentido, muito mais forte do que Armstrong, pois, na visão de Searle, a consciência é o fenômeno mais fundamental no domínio do psíquico.

\section{A CONCEPÇÃO DE CONSCIENCIA DE SEARLE}

John Rogers Searle é um dos grandes nomes da filosofia contemporânea, e uma figura de grande destaque na tradição analítica. Seus trabalhos exerceram uma grande influência na filosofia da linguagem, especialmente no campo da teoria dos atos de fala, e tiveram significativo impacto, também, no campo da filosofia da mente, principalmente atra- 
vés de sua crítica ao modelo computacional da mente, baseada no famoso "argumento do quarto chinês" (cf. Preston \& Bishop, 2002; Moural, 2003). Em sua perspectiva a respeito dos fenômenos mentais, a consciência ocupa um lugar central, pois ele articulou sua teoria em contraposição ao desprezo à consciência, reinante na filosofia analítica algumas décadas atrás. Searle defende que o caráter mental de qualquer fenômeno psíquico só pode existir em virtude das relações desse fenômeno com a consciência (cf. Searle, 1992, p. 84 [125-26]). E, diferente de Armstrong, que vê a consciência de um estado mental como decorrente do monitoramento desse estado por uma percepção de segunda ordem, Searle articulou um conceito de consciência muito mais complexo, um conceito que articula diversos aspectos relevantes para o fenômeno da consciência humana.

Searle concebe a consciência como uma característica que não pode ser analiticamente definida, (cf. Searle, 1992, p. 83 [123]; 2002, p. 21 [26]), por isso ele se limita a oferecer o que ele chama de uma "definição de senso comum" (cf. Searle, 2002, p. 21 [26]), isto é, indicações, através de exemplos, do fenômeno a ser estudado. Essa definição de senso comum proposta por Searle faz referencias a diversos aspectos, o que leva, por exemplo, o filósofo Ned Block a assumir um posicionamento crítico em relação a ela, pois a caracterização de Searle seria falha, "porque ela indica coisas demais, muitas consciências diferentes" (Block, 1997, p. 380). De fato, em sua definição de senso comum da consciência, Searle parece transitar de modo indiscriminado entre aquilo que David Rosenthal chamou de "consciência de 
criatura" e aquilo que ele denominou "consciência de estado". ${ }^{17}$

Ao caracterizar a consciência (cf., por exemplo, Searle, 1992, p. 83 [124]; Searle, 2002, p. 21 [26]), Searle alude sempre ao contraste entre as situações em que o indivíduo está desperto e as situações em que ele está, de diferentes formas, desacordado, o que é uma clara referência à consciência como propriedade de criaturas ou indivíduos. Ao mesmo tempo, ele se refere aos diversos estados mentais nos quais os indivíduos conscientes se encontram, numa clara referencia à consciência como característica de estados, eventos e processos mentais:

Por "consciência" eu entendo simplesmente aqueles estados subjetivos de sensibilidade [sentience] ou ciência [awareness] que começam quando alguém acorda pela manhã de um sono sem sonhos e continuam através do dia até que esse alguém adormeça à noite, entre em coma, morra ou se torne de outro modo, como diria alguém "inconsciente". (Searle, 2002, p. 7 [1-2]). ${ }^{18}$

Estados de consciência, pensados como propriedades de sujeitos conscientes, são caracterizados por uma propriedade essencial, que Searle vê como a combinação de três ca-

\footnotetext{
17 "Dois assuntos são frequentemente confundidos nas discussões sobre a consciência. uma questão é: o que é para um estado mental ser consciente. Supondo que nem todos os estados mentais são conscientes, nós queremos saber como os estados conscientes se diferenciam daqueles que não são. E ainda que todos os estados mentais fossem conscientes, nós ainda perguntaríamos em que consiste a sua consciência. Denominamos essa a questão da consciência de estado. Esse será meu principal tema no texto que segue. Mas nós não descrevemos apenas estados mentais como sendo conscientes ou não; nós também atribuímos consciência a criaturas. Assim, existe uma segunda questão, a questão sobre o que é para uma pessoa ou outra criatura ser consciente, ou seja, como criaturas conscientes se diferenciam daquelas que não são conscientes. Denominamos esta a questão da consciência de criatura." (Rosenthal, 1997, p. 729).

${ }^{18}$ Trata-se aqui de uma citação do texto "O problema da consciência", publicado originalmente em 1993.
} 
racterísticas, mutuamente implicadas: o caráter qualitativo, a subjetividade e a unidade (cf. Searle, 2002, p. 39 [56-57]). Quando o sujeito está consciente, ele vivencia diversos aspectos qualitativos, diversos modos como suas sensações, percepções e outros estados mentais são sentidos por ele. Há sempre um modo como é estar em um dado estado mental consciente (cf. Nagel, 1974, p. 436 [247]), o que torna nossas experiências algo dotado de qualidades. E esse caráter qualitativo já implica a subjetividade, pois se há uma qualidade, tem de haver um eu que a sente (cf. Searle, 2002, p. 39-40 [57-58]; Searle, 2004, p. 134-35). Os estados de consciência são, portanto, subjetivos porque eles só existem quando são vivenciados por um sujeito, seja um ser humano, seja alguma espécie de animal; há sempre um eu que possui a experiência (qualitativa) de se encontrar nesses estados de consciência (cf. Searle, 2002, p. 40-41 [58-59]).

E pelo fato de ser qualitativa e subjetiva, a consciência tem de ser unificada, porque nós vivenciamos nossos estados de consciência como uma unidade. De acordo com Searle (2004, p. 137), se tentássemos imaginar nossa consciência dividida em 17 partes, por exemplo, perceberíamos que estamos imaginando o surgimento de 17 campos independentes de consciência. Os diversos fenômenos mentais que vivenciamos, quando estamos conscientes, as diversas sensações, percepções, pensamentos, emoções, sempre se integram em uma experiência única, uma vez que "em formas não patológicas de consciência, nunca temos apenas, por exemplo, uma dor no cotovelo, uma sensação de calor ou a experiência de ver algo vermelho. Ao contrário, tudo isso ocorre simultaneamente em uma experiência conscien- 
te unificada" (Searle, 2002, p. 11-12 [9]). ${ }^{19}$

Essa característica da unidade será decisiva para nossas considerações, pois ela demarca aquela que, provavelmente, é a maior diferença entre as perspectivas de Searle e de Armstrong. Vimos que em uma perspectiva como a de Armstrong, que é, em certo sentido, uma perspectiva atomística, o modo de existência dos fenômenos inconscientes não é nada problemático. Em uma perspectiva na qual os fenômenos mentais são pensados, cada um, isoladamente, e na qual a consciência de um fenômeno mental é concebida como decorrente do seu monitoramento por um segundo fenômeno mental, distinto do primeiro, não há dificuldade para se compreender como um fenômeno mental existe quando ele não está sendo monitorado, pois ele continua a existir da mesma maneira que existia quando era monitorado (ou da maneira que existiria caso viesse a ser monitorado). ${ }^{20}$

Já em uma perspectiva holística como a de Searle, as coisas são mais complicadas, pois ele não vê os fenômenos mentais particulares como existências isoladas, ele não os vê como entidades que tem uma existência mais ou menos independente da consciência global, mas sim como entidades que existem integradas a esse campo unificado, de modo que se torna necessário um esforço maior para compreender como os fenômenos inconscientes existem já que não

\footnotetext{
${ }^{19}$ Cf. também Searle, 2004, p. 136; Searle, 2002, p. 41 [59-60]. No caso desta última referência, trata-se do texto "A consciência" publicado originalmente no ano 2000.

${ }^{20}$ Esse é um pressuposto das teorias de ordem superior que pode ser questionado (cf. Hardcastle, 2004, p. 283-85), mas que é efetivamente assumido por essas teorias. Em seu texto, Hardcastle se refere às teorias de pensamentos de ordem superior (como a de Rosenthal), mas entendo que sua crítica também poderia ser aplicada à teoria de Armstrong.
} 
estão integrados à consciência.

Searle enfatiza que existem dois aspectos dessa unidade da experiência consciente: por um lado a unidade simultânea em que uma série de diversos fenômenos mentais, que ocorrem em um dado momento, se unifica em um único campo consciente, e, por outro lado, a unidade da experiência ao longo do tempo, que faz com que, por exemplo, alguém, ao dizer uma frase, consiga conservar uma memória icônica do início da frase, de modo a ainda saber o que está dizendo ao termina-la (cf. Searle, 2002, p. 12 [9]; Searle, 2002, p. 42 [61]). Este segundo aspecto da unidade, um aspecto, por assim dizer, diacrônico (cf. Costa, 2002, p. 206), será de grande relevância para o problema discutido no presente trabalho, como será abordado a seguir.

Mas é interessante notar que Searle não pensa a integração dos fenômenos mentais ao estado unificado de consciência como um acúmulo de elementos mais ou menos independentes entre si. $\mathrm{O}$ holismo de sua concepção de consciência é bem mais forte do que isso. Em um estado de consciência como aquele em que eu me encontro agora, um estado no qual eu sinto o peso de meu corpo sobre o estofamento da cadeira, vejo as letras surgindo na tela do computador, sinto a temperatura abafada desta manhã, tudo isso como parte de uma única experiência, cada uma dessas sensações e percepções (assim como os pensamentos que vivencio agora) não são como os tijolos (building blocks) de uma construção composta, mas são concebidos por Searle como modificações de um campo de consciência basal, que pré-existe a essas sensações, percepções e pensamentos.

Searle especula que possa ser um erro pensar a 
consciência como composta de partes, pois pensar a consciência de modo realmente holístico pode ajudar a compreender mais claramente a combinação originária de subjetividade, qualidade e unidade numa única característica. De acordo com ele:

Em vez de pensar meu estado atual de consciência como constituído de várias partes - a percepção da tela do computador, o som do riacho lá fora, as sombras projetadas na parede pelo sol do fim da tarde - devemos pensar tudo isso como modificações e formas que o campo consciente basal subjacente assume depois de meus terminais nervosos periféricos serem acionados pelos vários estímulos externos. (Searle, 2002, p. 56 [86]).

Diante dessa hipótese da consciência como um fenômeno holístico, uma unidade de base, que se modifica para assumir a forma dos mais diversos fenômenos mentais (sempre qualitativos e subjetivos), coloca-se a pergunta a respeito dos fenômenos mentais inconscientes. Se o fenômeno mental consciente é aquele que é uma modificação do estado global descrito acima, qual é, nessa perspectiva, o modo de existência de um estado mental inconsciente?

A resposta de Searle é que, enquanto permanecem inconscientes, esses estados não possuem uma existência propriamente mental. Enquanto permanecem inconscientes, eles existem como padrões de atividade eletroquímica em arquiteturas neuronais, padrões de atividade cerebral que são capazes de causar estados mentais conscientes. Ou seja, estados inconscientes existem como disposições para o surgimento de estados mentais conscientes. Searle defende essa perspectiva acerca do inconsciente com base no seu argumento a favor do "princípio da conexão" entre consciência 
e intencionalidade. ${ }^{21}$ Mas, é importante ressaltar que tais estados inconscientes seriam, em uma teoria como essa, estados que não contribuem para as modificações do campo consciente basal. Esses estados (existindo como padrões de atividade eletroquímica nos neurônios) não se relacionariam com o campo unificado de consciência (caso o sujeito estivesse consciente), eles não introduziriam no campo unificado experiências que modificariam esse campo (cf. Searle, 2002, p. 55 [84]), mas preservariam a sua capacidade de faze-lo. A capacidade de emitir impulsos que mudassem o campo basal de consciência, gerando assim estados conscientes.

A esse respeito, é interessante notar que a visão de Searle da consciência como um campo unificado, que se unifica a cada instante e ao longo do fluxo temporal, o leva a uma compreensão diferente do tipo de exemplo usado por Armstrong para explicar sua visão da consciência introspectiva. A situação do motorista de caminhão, que subitamente se dá conta de ter percorrido uma longa distância, sem saber nada do que fez para conseguir chegar ao local onde se encontra na estrada, é vista por Armstrong como uma evidência de que houve atividade mental e percepção, que são duas formas elementares de consciência, na ausência da forma mais evoluída de consciência, a introspecção.

Em seu livro Mind: a Brief Introduction, em uma seção intitulada "consciência, memória e o eu", Searle discute um exemplo mais ou menos similar ao de Armstrong, mas ofe-

\footnotetext{
${ }^{21}$ Para analisar os argumentos de Searle a favor do princípio da conexão, cf. Searle, 1992, pp. 156 61 [224-31]; Searle, 2004, p. 246-47. Para uma discussão a respeito do argumento exposto em A redescoberta da mente, cf. Van Gulick, 1995.
} 
rece uma explicação diferente. Para ele, há um estado unificado de consciência de pouca intensidade, que por isso não é registrado na memória, mas é um estado que tinha de ser unificado durante o tempo em que ele existia ${ }^{22}$. Searle relata uma situação vivenciada por ele no dia 04 de janeiro de 1999 (cf. Searle, 2004, p. 156), quando esquiava na Califórnia, e subitamente, sofreu uma queda. Do seu próprio ponto de vista subjetivo, Searle se recorda de estar esquiando e de pensar que, por causa do ângulo de incidência da luz solar, era difícil ver as protuberâncias na pista, e a próxima coisa de que ele se lembra é de estar sentado perto do elevador, sem saber exatamente que dia era, pensando se era antes do natal ou após o ano novo. Houve um período de aproximadamente quinze minutos entre os dois eventos, do qual Searle não guarda a menor lembrança, mas as pessoas que viram sua queda disseram que seu esquis pararam subitamente e seu corpo fora lançado para a frente, caindo sobre a sua própria cabeça. Porém, segundo as testemunhas, Searle fora capaz de levantar, pegar os óculos na neve, recolocar os esquis e descer o restante do percurso até a base da montanha com muita cautela (o que nos lembra da sequência complexa de ações e percepções que o motorista do exemplo de Armstrong tem de ter desempenhado para conseguir se deslocar pela estrada). Mas ao chegar ao sopé, Searle não respondia a perguntas nem iniciava qualquer conversação. As pessoas que estavam presentes disseram que ele se comportava como se estivesse completamente

\footnotetext{
${ }^{22}$ Se considerarmos que, na visão de Armstrong, a consciência introspectiva é responsável por integrar diversos estados e processos mentais, que na ausência dela existem dissociados, perceberemos o quanto essa visão é diferente da de Searle, para quem (supostamente) os estados e processos efetivamente mentais só existem integrados ao campo unificado de consciência.
} 
consciente, ainda que não totalmente normal. Desse relato a respeito de seu pequeno acidente, completamente esquecido, Searle conclui:

Eu estou convencido, pelo meu próprio caso, de que eu estava consciente durante o período, mas era simplesmente incapaz de registrar minhas experiências conscientes na memória. Não tenho absolutamente nenhuma recordação, mas eu creio que me comportei de um modo no qual eu não poderia ter me comportado se não estivesse consciente, ainda que eu não estivesse cem por cento normal. O que temos nesse caso é um nível baixo de consciência não registrado na memória. (Searle, 2004, p. 157, grifo meu).

Diante da impossibilidade de um acesso direto, já que ele não tem lembrança de suas vivências durante aqueles quinze minutos, Searle se baseia no seu comportamento, testemunhado por outras pessoas no local, para concluir que havia, naquele período esquecido, um estado de consciência que, como tal, só poderia ser subjetivo, qualitativo e unificado, mas que esse estado foi perdido, porque sua baixa intensidade não permitiu seu registro na memória. Nesse sentido, interpreto que Searle está atribuindo a aquele estado de consciência, esquecido, uma falha na unidade diacrônica da experiência.

Penso que - ao mesmo tempo em que a questão da memória de eventos é um ponto comum - essa explicação de Searle evidencia uma importante diferença de sua teoria com a de Armstrong. Na concepção do filósofo australiano, uma pessoa na situação do motorista de caminhão do seu exemplo (ou na situação de queda durante o esqui descrita por Searle), dispõe de formas mais elementares de consciência, consciência mínima (atividade mental) e consciência 
perceptiva, mas carece da forma mais sofisticada, a consciência introspectiva que apreende processos mentais paralelos, possibilitando sua integração. Para Armstrong, a ausência de introspecção parece estar ligada à falta de memória experimentada pelo motorista, já que os processos mentais não monitorados introspectivamente terminam esquecidos. Nesse caso, os processos mentais dos quais não se guardou lembrança são concebidos como processos desarticulados entre si, mas que tem a mesma natureza que teriam se o motorista dispusesse de consciência introspectiva.

Já na explicação de Searle, a falta de memória decorre de uma anomalia do estado global de consciência, mas tinha que haver, de qualquer maneira, uma integração (uma unidade sincrônica), porque se tratava, sim, de uma estado de consciência, e um tal estado tem como uma característica essencial a unidade, ou seja, os estados mentais, durante aquele período que foi esquecido, não poderiam, como pensa Armstrong, estar desarticulados entre si. As sensações, percepções e intenções que Searle teve que vivenciar pata ter sido capaz de recuperar os esquis e descer a montanha, tem que ter sido unificados em um único estado de consciência. Elas apenas não puderam ser fixadas na memória, o que não significa que não houve, durante o período esquecido, um estado de consciência (mesmo que fosse um estado, em certo sentido, deficiente). A situação do acidente, portanto, não é vista por Searle como uma situação na qual houve atividade mental desprovida de consciência.

Apesar dessa importante diferença (a ausência de integração entre os estados mentais na teoria de Armstrong, e a integração dos estados mentais em um campo unificado 
- embora carente de unidade diacrônica - na teoria de Searle) parece haver uma interessante similaridade entre as duas teorias, pois Searle admite que há consciência no período em que ele esteve sob o efeito da queda, ainda que fosse uma consciência, por assim dizer, "imperfeita" ou "falha”, e no caso (análogo) do motorista de caminhão, Armstrong entende que havia consciência, em sentidos mais limitados desse termo (ou seja: consciência mínima e consciência perceptiva), mas não havia consciência no sentido mais importante da palavra (a consciência introspectiva), o que é bastante compatível com a ideia de uma consciência "imperfeita". 23

Mas, no meu modo de entender, há um outro elemento da concepção de Searle sobre o inconsciente que sugere outra similaridade mais importante com a teoria de Armstrong. Porém, nesse caso, seria uma similaridade certamente indesejada por Searle. Entendo que atribuições de eficácia causal aos estados inconscientes (potencialmente mentais) tem como consequência indesejável o compromisso com uma forma de existência mental, porém independente da consciência. ou seja: a atribuição de eficácia causal resulta no compromisso com a visão oposta ao princípio da conexão que Searle quer defender.

\section{SEARLE SOBRE A EFICÁCIA CAUSAL DOS FENÔMENOS MENTAIS INCONSCIENTES}

Searle defende a eficácia causal de fenômenos inconsci-

\footnotetext{
${ }^{23}$ O termo "imperfeita" não aparece na discussão de Searle sobre o acidente que ele sofreu. Utilizo esse termo como parte de minha interpretação do exemplo.
} 
entes tanto no caso de fenômenos caracterizados (em condições normais) por aspecto qualitativo, como sensações e percepções, quanto no caso de fenômenos caracterizados (quando conscientes) por intencionalidade genuina, como crenças e desejos. No que diz respeito aos fenômenos qualitativos, Searle defende sua eficácia causal tomando por base situações que envolvem dores, que parecem preservar sua eficácia causal mesmo quando desprovidas de consciência. Nessas situações, ele entende ser razoável concluir que essa eficácia causal está radicada num processo neurofisiológico subjacente, que permanece capaz de gerar o comportamento apropriado à dor, mesmo quando ele não produz a sensação consciente de dor (cf. Searle, 1992, p. 165 [237]). E ele adapta a mesma explicação para o caso de estados intencionais inconscientes (portanto apenas potencialmente mentais, segundo as afirmações explícitas de Searle): mesmo quando o estado intencional não está consciente, há uma estrutura neurobiológica capaz de causar o comportamento apropriado a alguém que se encontra nesse estado, mesmo quando essa estrutura não produz tal estado intencional como parte de seus pensamentos conscientes (cf. Searle, 2004, p. 244-45).

Temos, assim, um cenário no qual uma determinada entidade concreta e particular (um determinado processo cerebral, situado em determinadas porções do espaço e existente em determinados períodos do tempo) possui um incontável número de propriedades, entre as quais se encontram determinadas capacidades causais. Mas enquanto algumas dessas capacidades existem de modo ocorrente, outras delas existem de modo disposicional. Um processo no 
cérebro, enquanto uma vasta série de interações eletroquímicas ocorrendo em uma ampla arquitetura composta de neurônios, tem o potencial de causar muitas coisas (em interação com outros processos cerebrais ou com outros elementos do organismo), mas entre as coisas que ele pode causar estão, por um lado, efeitos comportamentais e, por outro lado, estados mentais conscientes.

O caso é que nossa convicção de que um estado mental consciente possui eficácia causal está indissociavelmente ligada à ideia de que essa eficácia é exercida como decorrência das características definidoras desse estado mental. Uma sensação consciente afeta nosso comportamento do modo específico como ela afeta em decorrência de seu específico aspecto qualitativo (a dor nos perturba e nos afasta em virtude de seu aspecto qualitativo peculiar, assim como o prazer nos gratifica e nos atrai em virtude de sua qualidade específica - o modo específico como nós o sentimos). Já um estado intencional consciente, como uma crença, um desejo ou uma intenção, afeta o nosso comportamento do modo específico como ele afeta em virtude de seu conteúdo representativo, com sua específica forma aspectual ${ }^{24}$, do contrário, não faria sentido pensar que agimos do modo que agimos em virtude daquele exato estado intencional.

Se tenho o desejo de assistir a um determinado filme e vou ao cinema para assisti-lo, parece-me que minha ação (ir

\footnotetext{
${ }^{24}$ Searle esclarece o conceito de forma aspectual nos seguintes termos: "Um homem pode acreditar, por exemplo, que a estrela no céu é a Estrela da Manhã sem acreditar que é a Estrela Vespertina. Um homem pode, por exemplo, querer beber um copo d'água sem querer beber um copo de H2O. Há um número indefinidamente grande de descrições corretas da Estrela Vespertina e de um copo d'água, mas acredita-se em algo em relação a elas, ou deseja-se algo delas somente sob determinados aspectos e não sob outros. Toda crença e todo desejo, na verdade todo fenômeno intencional, tem uma forma aspectual." (Searle, 1992, p. 157 [225-26]).
} 
a tal cinema, em tal data e horário) foi consequência de meu desejo de assistir, por exemplo, a Gritos e sussurros, de Ingmar Bergman (e não outro filme qualquer), assim como essa ação foi, em parte, consequência de minha crença de que esse filme (e não outro) seria exibido naquele cinema, naquela data, naquele horário. Ou seja: os conteúdos bem determinados do meu desejo (de assistir aquele filme) e de minha crença (de que ele seria exibido em uma retrospectiva naquele dia, hora e local), com as formas aspectuais bem determinadas desse desejo e dessa crença, tem que ter desempenhado um papel decisivo na causação daquela ação específica, do contrário eu poderia ter ido, por exemplo, para outro lugar, ou poderia ter desejado fazer alguma outra coisa. Mas, além disso, se eu efetivamente pratiquei a ação de ir ao cinema naquele dia, hora e lugar, parece sem sentido supor que os conteúdos e formas aspectuais desses estados não desempenharam nenhum papel na causação de minha ação, pois isso equivaleria a pensar que eu, na verdade, não agi do modo que eu agi por causa daqueles específicos estados intencionais (o desejo de assistir a aquele filme, somado à crença de que ele seria exibido em tal dia e hora).

É claro que faria sentido supor que aquele desejo e aquela crença consciente que eu vivenciava não eram as verdadeiras causas de minha ação, e que eu fui ao cinema porque, inconscientemente, desejava encontrar tal pessoa ou desejava evitar uma outra situação naquele mesmo horário. Mas o ponto decisivo aqui é que, a partir do momento em que suponho que algum estado intencional é a causa de uma ação minha, sou racionalmente obrigado a supor que 
o conteúdo representativo desse estado (assim como a forma aspectual desse conteúdo) desempenhou um papel essencial na causação daquela ação específica.

Mas se os efeitos específicos de um estado mental consciente estão indissociavelmente ligados às características definidoras desse estado mental (seu aspecto qualitativo no caso de sensações e percepções, ou seu conteúdo representativo - com sua determinada forma aspectual - no caso de estados intencionais), então esse mesmo vínculo (entre os efeitos causais e as características definidoras) se impõe também no caso dos estados mentais inconscientes, do contrário, não faria sentido supor que se trata de uma eficácia causal pertencente ao fenômeno mental (que, neste caso, carece de consciência). O que estou tentando defender é que a ideia de uma eficácia causal propriamente mental exige que as características definidoras de um fenômeno mental particular desempenhem um papel indispensável na causação dos efeitos específicos desse fenômeno mental.

$\mathrm{E}$ isso tem como consequência que, para exercer sua eficácia causal específica, um estado inconsciente (seja qualitativo, seja intencional) tem que exerce-la em virtude de suas características especificamente mentais (aspecto qualitativo, no caso de estados sensoriais, e forma aspectual, no caso de estados intencionais). Mas se é assim, então a eficácia causal de um estado mental inconsciente exige que esse estado possua uma existência propriamente psíquica independentemente da consciência, de modo que, ao aceitar a eficácia causal dos fenômenos mentais inconscientes (uma eficácia que, no meu entendimento, é muito difícil de ser negada) Searle está, inadvertidamente, se comprometendo 
com premissas incompatíveis com o princípio da conexão entre o inconsciente e a consciência (cf. Searle, 2004, p. 246), de maneira que sua teoria se revela incoerente.

No fundo, o que Searle está defendendo é uma perspectiva na qual existe um fenômeno físico, um processo cerebral - implementado em uma estrutura neuronal altamente complexa - que possui uma larga série de propriedades (a) ocorrentes e outra larga série de propriedades (b) disposicionais. No caso do fenômeno mental consciente, esse processo cerebral causa não só (i) determinados efeitos comportamentais, mas também (ii) o próprio estado mental em forma consciente. Já no caso do fenômeno inconsciente, em determinadas situações (aquelas nas quais esses fenômeno inconscientes causam algo), o processo cerebral causa apenas os efeitos comportamentais. O problema é que se tais efeitos decorrem causalmente de fenômenos mentais quaisquer (sejam conscientes, sejam inconscientes), esses efeitos tem que ser decorrentes de características mentais bem determinadas desses fenômenos - sejam qualitativos, como dores, sejam intencionais, como crenças e desejos. Portanto, se um fenômeno mental inconsciente tem efeitos causais no mundo, suas características mentais definidoras - aspecto qualitativo e/ou conteúdo representativo - tem que existir efetivamente. Desse modo, a disposição de causar um fenômeno consciente aparece como uma propriedade menor do fenômeno em questão, pois há uma existência psíquica, seja o fenômeno consciente ou não. Esse é uma conclusão que Searle, certamente, não estaria disposto a aceitar. 


\section{CONCLUSÃO}

Searle adere a aquela que David Rosenthal denominou de concepção cartesiana da consciência (cf. Rosenthal, 1986, p. 331), na medida em que ele a considera como o fundamento do psíquico (cf. Searle, 1992, p. 83 [125-26]). Porém, ao mesmo tempo, ele pretende aceitar em sua teoria os indícios, segundo ele incontornáveis (cf. Searle, 1992 p. 151 [217]; Searle, 2004, p. 250), de que existem fenômenos mentais inconscientes, que exercem influência decisiva sobre nossas ações. Como vimos, a maneira que ele encontra para conciliar as duas coisas - (a) o caráter fundamental da consciência para o psíquico, e (b) a ideia de um psiquismo inconsciente - é defender uma concepção disposicional do inconsciente, segundo a qual os fenômenos inconscientes não possuem uma existência mental efetiva, mas possuem apenas uma existência disposicional, codificada na estrutura física do cérebro.

Minha objeção à teoria de Searle sobre a consciência (e o inconsciente) é que a eficácia causal que ele atribui aos fenômenos inconscientes é incompatível com essa visão disposicional. Não incompatível no sentido de que um dado fenômeno mental não possa ser caracterizado como disposicional em um sentido mais brando, no qual o fenômeno é caracterizado apenas parcialmente em termos disposicionais, o que não impede que ele possua, também, uma existência ocorrente, ou seja, efetiva. ${ }^{25}$ De fato, Searle

\footnotetext{
25 Refletindo sobre uma ideia exposta a ele por Ernest Sosa, Rosenthal discute a distinção entre duas concepções disposicionais nos seguintes termos: "Alguém pode tentar sustentar a ideia de que todos os fenômenos mentais são conscientes insistindo que estados não conscientes seriam meras disposições. Somente estados ocorrentes estariam qualificados como genuínos estados menCont.
} 
parece conceber os fenômenos inconscientes dessa maneira disposicional mais "branda", ou seja, parece concebe-los como fenômenos que possuem tanto capacidades ocorrentes (atualizadas) quanto capacidades disposicionais (isto é: potenciais) - cf. Searle, 2004, pp. 243-45.

Mas, por outro lado, a eficácia causal do inconsciente é incompatível com essa visão disposicional branda no sentido de que os efeitos causais desses fenômenos inconscientes tem que ser concebidos como consequência de propriedades mentais ocorrentes. Pois se um desejo está desconectado do campo de consciência mas, mesmo assim, é capaz de causar uma ação, a única forma como esse desejo pode ter produzido esse efeito é através de sua específica forma aspectual, de modo que esta forma, simplesmente, não pode estar existindo (no momento da causação inconsciente daquele agir) como algo não mental.

Neste ponto, é importante perceber o quão enfaticamente Searle demarca a diferença entre um estado mental consciente e sua contraparte disposicional, pois ele enfatiza que a forma aspectual só existe de maneira consciente. Nenhuma caracterização em termos objetivos (sejam termos comportamentais, sejam termos neurofisiológicos) é capaz de expressar a forma aspectual de um estado intencional, o

\footnotetext{
tais, e estes, alguém poderia alegar, seriam todos conscientes. Essa sugestão confunde dois modos de se ser disposicional. Por 'estado mental disposicional' alguém pode querer dizer um estado que é simplesmente uma disposição para estar em um estado mental ocorrente. Mas alguém pode também ter em mente um estado mental cuja natureza podemos proveitosamente descrever ao menos parcialmente em termos disposicionais. Ser disposicional do primeiro modo é incompatível com ser ocorrente, mas ser disposicional no segundo sentido não é." (Rosenthal, 1997, p. 732). É fácil perceber que a concepção esboçada no início da citação corresponde em linhas gerais à visão de Searle. E entendo que, quando Rosenthal distingue dois sentidos do termo "disposicional", o segundo sentido mencionado por ele (um sentido parcial que é compatível com ser ocorrente) é o sentido que Searle tem em mente.
} 
que parece indicar que a forma aspectual só existe quando é subjetivamente vivenciada. Discutindo o que poderia ser uma abordagem neurocientífica da forma aspectual, Searle afirma:

Mesmo que tivéssemos uma ciência perfeita do cérebro, e ainda que tal ciência perfeita do cérebro nos permitisse colocar nosso cerebroscópio no crânio de uma pessoa e perceber que ela queria água, mas não $\mathrm{H}_{2} \mathrm{O}$, ainda assim haveria uma inferência - ainda teríamos que ter algum conexão nomológica que nos habilitasse a inferir, a partir de nossas observações da arquitetura neuronal e das descargas neurônicas, que eram realizações do desejo de água, e não do desejo de $\mathrm{H}_{2}$ O. (Searle, 1992, p. 158 [227-28], grifo meu).

Mas a mera inferência, segundo Searle, não pode ser jamais uma especificação efetiva do intencional, de modo que o intencional parece estar ausente do puramente fisiológico. E Searle enfatiza que " a ontologia dos estados mentais inconscientes, durante o tempo em que são inconscientes, consiste inteiramente na existência de fenômenos puramente neurofisiológicos." (Ibid., p. 159 [228], grifado no original). Disso eu concluo que a forma aspectual, numa concepção como essa, não poderia estar presente no nível puramente biológico. E por isso, quando Searle aceita a causação inconsciente ele está ferindo esse núcleo de sua teoria, pois "durante o tempo em que os estados estão totalmente inconscientes, não há simplesmente nada lá, exceto estados e processos neurofisiológicos" (Ibid., p. 159 [229]), e tais estados e processos nunca são suficientes para determinar a forma aspectual de um estado intencional genuíno.

E a consequência mais ampla que deduzo dessa dificul- 
dade da visão de Searle sobre o inconsciente é que ela significa um abalo, também, na concepção cartesiana do mental, pois essa dificuldade da visão disposicional abala a plausibilidade da tese de que a consciência é uma propriedade essencial dos fenômenos mentais. Ao considerar a consciência como essencial à mentalidade, Searle se vê obrigado a articular uma tortuosa teoria disposicional do inconsciente que, todavia, não é coerente com a eficácia causal dos fenômenos inconscientes.

Abstract: This paper examines David Armstrong's and John Searle's accounts of consciousness and of unconscious mental phenomena. Whereas Armstrong sees consciousness as a consequence of a second-order perception, so that an unconscious phenomenon is just a mental phenomenon which is not perceived, Searle sees consciousness as a global state, which makes his view of consciousness more complicated. Unconscious mental states are nothing but patterns of neuronal activity, patterns which are capable to cause conscious mental states under the appropriate circumstances. However, whereas Armstrong's theory is perfectly coherent, Searle's view is inconsistent, since the causal efficacy he assigns to unconscious phenomena is incompatible with the fundamental role he assigns to consciousness in the domain of mental phenomena

Key-words: consciousness, perception, unconscious, causal efficacy.

\title{
REFERÊNCIAS
}

ADAM, C; TANNERY, P. Ouvres de Descartes - Meditationes de prima philosophia. Paris: Vrin, 1996.

- (Org.). Ouvres de Descartes - Méditations et príncipes (traduction française). Paris: Vrin, 1996.

\author{
ARMSTRONG. A. A Materialist Theory of Mind. Lon- \\ don: Routledge \& Kegan Paul, 1968.
}


. "What is Consciousness?". In: Block, N. (Org.); Flanagan, O. (Org.); Güzeldere, G. (Org.). The Nature of Consciousness: Philosophical Debates. Cambridge (Massachusetts): MIT Press, p. 721-728, 1997.

.The Mind-Body Problem: An Opinionated Introduction. Oxford: Westview Press, 1999.

BLOCK, N. "On a Confusion About a Function of Consciousness" In: Block, N. (Org.); Flanagan, O. (Org.); Güzeldere, G. (Org.). The Nature of Consciousness: Philosophical Debates. Cambridge (Massachusetts): MIT Press, p. 375-415, 1997.

BRENTANO, F. Psychologie vom empirischen Standpunkt. $2^{\mathrm{a}}$ ed. Leipzig: Meiner, 1924.

. Psychology from an empirical standpoint. London: Routledge \& Kegan Paul, 1995.

CHALMERS, D. "Facing Up To The Problem of Consciousness". Journal of Consciousness Studies. v. 2, n. 3, p. $200-219,1995$

COSTA, C. Uma introdução contemporânea à filosofia. São Paulo: Martins Fontes, 2002.

DESCARTES, R. Discurso do método; Meditações; Objeções e Respostas; As Paixões da Alma; Cartas. 2. ed. São Paulo: Abril Cultural (Os Pensadores), 1979.

FREUD, S. "Einige Bemerkungen über den Begriff des Unbewussten in der Psychoanalyse (1912)". In: Psychologie des Unbewussten. Frankfurt am Main: Fischer Taschenbuch Verlag, p. 25-36, 1982. 
GENNARO, R. Consciousness and Selfconsciousness: a Defense of the Higher Order Thought Theory of Consciousness. Amsterdam/Philadelphia: John Benjamins Publishing, 1996.

. Higher-Order Theories of Consciousness: An Anthology. Philadelphia: John Benjamins Publishing Company, 2004.

GÜZELDERE, G. "Introduction - Many Faces of Consciousness: A Field Guide" In: Block, N. (Org.); Flanagan, O. (Org.); Güzeldere, G. (Org.). The Nature of Consciousness: Philosophical Debates. Cambridge (Massachusetts): MIT Press, p. 1-67, 1997.

HARDCASTLE, V. "HOT Theories of Consciousness: More Sad Tales of Philosophical Intuitions Gone Astray". 2004.

HARRÉ, R. "Dispositions and Powers" In: W. H. NewtonSmith (ed.). A Companion to the Philosophy of Science. Oxford: Blackwell, pp. 97-101, 2001.

HUSSERL, E. Logische Untersuchungen II: Untersuchungen zur Phanomenologie und Theorie der Erkenntnis. Den Haag: Martinus Nijhoff, 1984.

. Investigações Lógicas: Segundo volume, parte I. Investigações para a Fenomenologia e Teoria do Conhecimento. Trad. Pedro M. S. Alves. Rio de Janeiro: Forense Universitária, 2012.

KRIEGEL, U. Consciousness and Self-consciousness. The Monist, v. 87, n.2, p. 182-205, 2004. 
MOURAL, J. The Chinese Room Argument. In: Smith, B. (Org.) John Searle. Cambridge: Cambridge University Press, p. 214-60, 2003.

NAGEL, T. "What Is It Like To Be a Bat?" In: Philosophical Review, v. 83, p. 435-50, 1974.

. "Como é ser um morcego?". Cadernos de História e de Filosofia da Ciência, v. 15, n.1, p. 245-62, 2005.

PRESTON, J; BISHOP, M. Views into the Chinese Room: New Essays on Searle and Artificial Intelligence. Oxford: Oxford University Press, 2002.

ROSENTHAL, D. Two Concepts of Consciousness. Philosophical Studies, v. 49, p. 329-59, 1986.

A Theory of Consciousness. In: Block, N. (Org.); Flanagan, O. (Org.); Güzeldere, G. (Org.). The Nature of Consciousness: Philosophical Debates. Cambridge (Massachusetts): MIT Press, p.729-753, 1997.

SARTRE, J. La transcendece de l'Ego - esquisse d'une description phénoménologique. Paris: Vrin, 1966.

. O imaginário: psicologia fenomenológica da imaginação. São Paulo: Editora Ática, 1996.

- A transcendência do ego - esboço de uma descrição fenomenológica. Cadernos Espinosanos, v. XXII, p. 183228, 2010.

Searle, J. The Rediscovery of the Mind. London: MIT Press, 1992. 
. A Redescoberta da Mente. São Paulo: Martins Fontes, 1997.

. Consciousness and Language. Cambridge: Cambridge University Press, 2002.

A Brief Introduction. Oxford: Oxford University Press, 2004.

. Consciência e linguagem. São Paulo: Martins Fontes, 2010.

VAN GULICK, R. Why the Connection Argument Doesn't Work. Philosophy and Phenomenological Research, v. LV, n. 1, p. 201-207, 1995.

Consciência. Investigação filosófica, v. E2, 2012. 